\title{
Materials Researcher Switches from Brake Rotor Materials to Crash Dummies
} Alan Taub

A little over two years ago, I moved from Ford's Scientific Research Laboratory and joined Product Development as manager of the Vehicle Crash Safety Engineering Department. This new career focus has been accompanied by a number of changes. The most obvious has been with my family. For 20 years, I would go home and describe breakthroughs in superconducting magnets and brake rotor materials. However, this failed to impress my family. But when they found out that I worked with crash dummies, all of a sudden I had a job they could relate to. I have received similar reactions from friends. While I was seldom asked about progress in understanding fatigue of aluminum engine blocks, everyone wanted to know the latest crash ratings of the vehicles they wished to purchase.

In my present position, I lead more than 200 engineers who design and verify the safety crash performance of our vehicles. The department's engineering sections begin with simplified concept models that are used to establish a vehicle architecture capable of meeting the crash performance targets. The design becomes more detailed as the program proceeds, resulting in complete finite element models that are exercised to evaluate how the vehicle will perform in a crash. These sophisticated computer-aided engineering analyses allow us to simulate a number of different crash modes in great detail. Once the performance is optimized, vehicle prototypes are constructed and tested in many con-

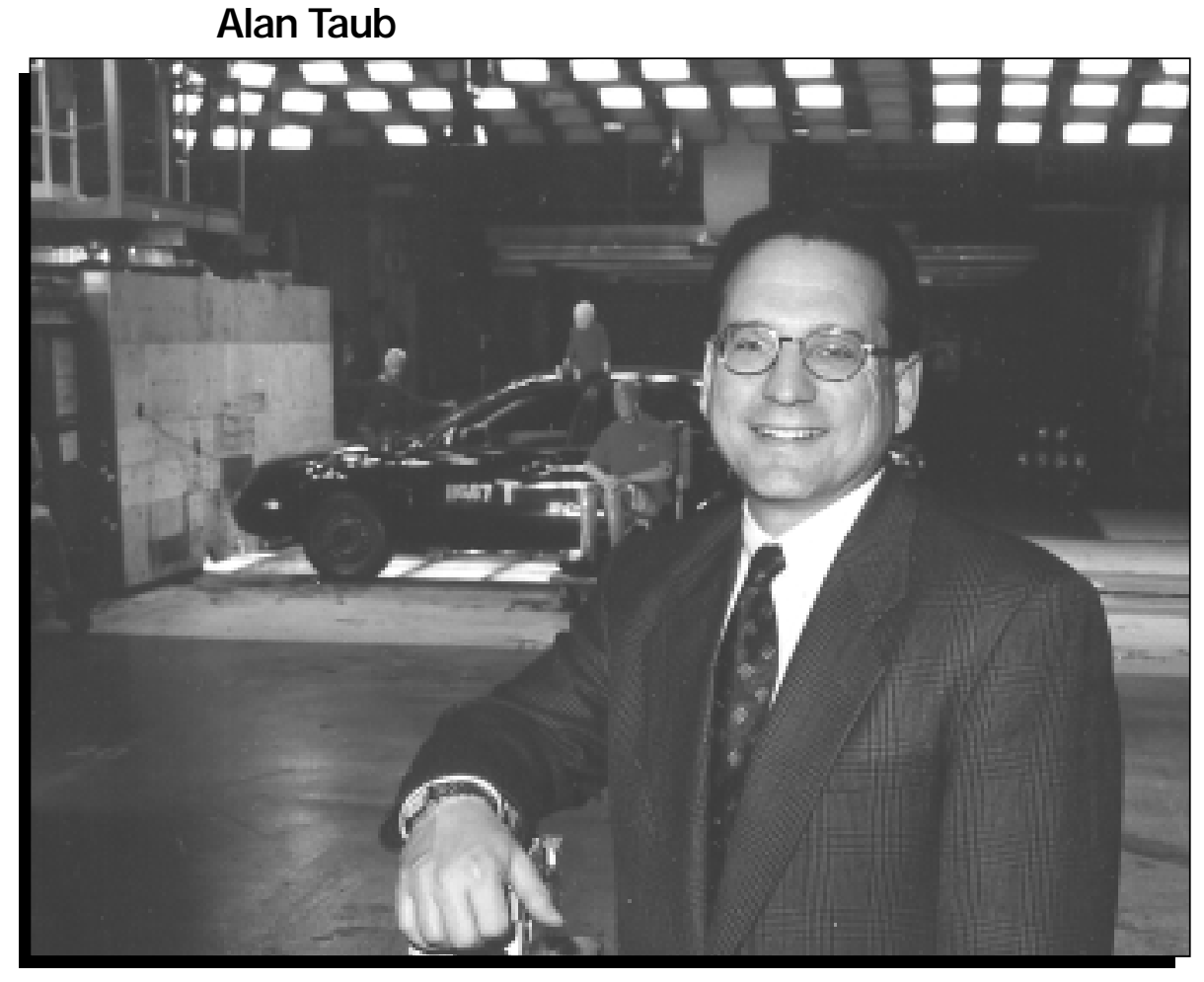

Alan Taub works with crash dummies in his role as manager of the Vehicle Crash Safety Engineering Department at Ford.

figurations by impacting both barriers and other vehicles. On a typical vehicle program, several hundred crash simulations and more than 50 physical crashes are performed. These tests employ highly complex instrumentation to fully characterize both the structural performance of the vehicle and the forces on the occupant 
dummies. Extensive biomechanical research in the industrial, government, and academic laboratories has enabled us to relate the accelerations and deflections of the dummy to the damage limits of humans. The vehicle design is improved until the dummy performance during a crash meets and, in most cases, exceeds government regulations. In addition to regulatory compliance, Ford's internal safety guidelines and due care requirements address crash performance in other situations that could be experienced in the real world. Our vehicles are released to the marketplace only after successful completion of these tests.

I cannot say that when I entered graduate school in materials science, I was planning for this position. In fact, the first 20 years of my career followed the traditional path for industrial materials researchers. After completing my PhD program, I joined the Materials Properties and Processes Laboratory at General Electric's Corporate Research and Development Center. There I performed research on amorphous metals for transformers, hightemperature intermetallics for aircraft engines, and superconducting materials for medical magnetic resonance imaging. I then became manager of that department and a few years later moved to Ford's Scientific Research Laboratory as manager of the Materials Science Department.

Switching companies in mid-career turned out to be a challenging experience. While materials research involves the same basic technical approaches no matter where the work is performed, the effects of corporate culture on the nature of the projects that are undertaken and the way that the work is conducted should not be underestimated. It was also a particularly interesting time to move to the automotive research arena. The Partnership for New Generation of Vehicles was launched shortly after I moved to Ford's Research Laboratory. That program enabled the researchers at Ford, Chrysler, and General Motors to perform cooperative pre-competitive work with each other and with the national laboratories. Those interactions proved to be a major challenge as we learned how to share our research efforts while maintaining our competitive position in the marketplace.

Ford's Scientific Research Laboratory is in the same building complex and closely tied to the product engineering division. By participating in and helping to drive several new materials processes and methodologies from the research phase through implementation, I was exposed to

Career Clips explores the range of career possibilities in, or related to, materials science. the product engineering world and was intrigued by what I saw. Fortunately, one of the advantages of working for a large corporation is that a breadth of opportunities are available. I was able to transfer to an engineering function and experience being much closer to the product.

Moving from research to engineering turned out to be a much greater change than moving to an entirely new company had been. I was totally out of my comfort zone as a materials scientist trying to manage a department of mechanical engineers who were actually impacting the product on a daily basis. The pace was much faster and the stress level much higher than the research environment. This was offset by the satisfaction of directly affecting the product, particularly since we were improving the safety performance of the vehicles that my friends and family drive.

I quickly learned that there are many common principles to leading technical personnel in both research and engineering environments. In fact, the rigors of indepth research training provide a strong background for the engineering arena. The laws of physics are the same in both worlds, which means the same management approach can be applied: hire the right people, challenge them to work on the key problems, and provide both the resources and recognition to motivate continued progress. 